\title{
Glomus tumor of the stomach
}

\author{
Pelin Yıldız', Zuhal Gücin'1, Dilek Sema Arıc1', Fatma Ümit Malya², Birol Baysal ${ }^{3}$
}

\begin{tabular}{|c|c|}
\hline ABSTRACT & $\begin{array}{l}\text { Glomus tumor is a rare benign mesenchymal neoplasm derived from the glomus body, an arteriovenous shunt } \\
\text { mainly located in dermis and subcutis. The most common localization of this tumor is extremities, especially } \\
\text { nailbed. Glomus tumor in the gastrointestinal system is a rare condition. Here we report a gastric glomus tumor to } \\
\text { raise awareness of this tumor and show the difficulties in the diagnosis. }\end{array}$ \\
\hline & Keywords: Gastric, glomus, tumor, uncommon \\
\hline
\end{tabular}

Cite this paper as: Yıldız P, Gücin Z, Arıı DS, Malya FM, Baysal B. Glomus tumor of the stomach. Turk J Surg 2018; 34: 62-64.

'Department of Pathology, Bezmialem Vakif University School of Medicine, ístanbul, Turkey ${ }^{2}$ Department of General Surgery, Bezmialem Vakif University School of Medicine, İstanbul, Turkey

${ }^{3}$ Department of Gastroenterology, Bezmialem Vakif University School of Medicine, i̇stanbul, Turkey

\section{Address for Correspondence Pelin YıIdız e-mail: drpelinyildiz@gmail.com \\ Received: 20.04.2015 Accepted: 20.06.2015 Available Online Date: 03.01.2018 \\ CCopyright 2018 by Turkish Surgical Association

\section{INTRODUCTION}

Glomus tumor is a rare benign mesenchymal neoplasm. As the name indicates, the tumor arises from the glomus body, which is an arteriovenous anastomosis, functioning without an intermediary capillary bed (1). It represents approximately $2 \%$ of all soft tissue tumors. The majority of glomus tumors occur in the distal extremities especially in the fingers, particularly in the subungual region and the skeletal muscle (2). The stomach is an exceptional site for glomus tumor. The first case of gastric glomus tumor was reported in 1951 by Kay et al. (3). Since then, few cases have been reported (1). Gastric glomus tumors, which are located in the antrum or pylor, are typically seen in the submucosa and muscularis propria. The tumors are generally benign. However, rarely they may show malignant behavior, according to localization, size, high nuclear grade, and atypia $(4,5)$.

\section{CASE PRESENTATION}

A 68-year-old man was admitted to our emergency service with an upper gastrointestinal bleeding episode. The patient was hemodynamically stabile and laboratory results were in normal limits. An upper gastrointestinal endoscopy was planned (Figure 1). Endoscopy revealed a submucosal mass located in the antrum. Due to the submucosal mass existence, an endoultrasonographic evaluation was performed. A hypervascularized mass of $4 \mathrm{~cm}$, with microcalcifications inside, was found in muscularis propria (Figure 2). With prediagnosis of gastrointestinal stromal tumor (GIST), endoultrasonographic fine-needle aspiration was performed. Hypocelluler biopsy had few SMA positive smooth muscle cells, fibrin, and blood. Immunohistochemically, CD34, S100, DOG1, and CD117 were negative and Ki-67 index was 1\%. With these findings, biopsy was not consistent with GIST. The patient was subjected to further investigation. Abdominal contrast-enhanced computed tomography (CT) was performed and revealed a well-circumscribed, homogeneously enhanced $25 \times 23 \mathrm{~mm}$ solid submucosal tumor located in the gastric antrum in the greater curvature (Figure 3). The tumor was interpreted with a prediagnosis of neuroendocrine tumor (NET). Surgery was planned with prediagnosis of GIST and NET. Additional tests for CEA, CA 19-9, Chromogranin A, and gastrin levels were in normal limits. Wedge resection and a partial omentectomy were performed.

In macroscopic examination, $5.5 \times 2.5 \times 2.5 \mathrm{~cm}$ nodular mass, arising from the submucosa and extending through the muscularis of the stomach, was observed. The excised specimen had clear margins. The cut surface of the mass was white and hyperemic. In microscopic examination, it was a highly vascular tumor composed of thinwalled vessels. The vessels were surrounded by monomorphic, small, round-to-polygonal cells forming nests, sheets, and strands. The cells had centrally located nuclei, inconspicuous nucleoli, and clear-to-eosinophilic cytoplasm with sharply defined cell borders (Figure 4). There were neither necrosis nor mitosis in the tumor. Collagen type IV, an immunohistochemical marker in favor of glomus tumor, was focally and mildly positive. Immunohistochemically, SMA (Figure 5) and vimentin (Figure 6) were diffusely positive, and caldesmon was focally positive in tumor cells. CD 117, DOG 1, S100, CD34, chromogranin, synaptophysin, CD56, CD57, PGP9.5, and desmin were all negative. Ki-67 index was 1\%, consistent with the former biopsy. Clinical, morphologic, and immunohistochemical findings were consistent with the diagnosis of glomus tumor.

After the diagnosis of glomus tumor, the patient underwent systemic examination, but no evidence of metastasis was found. The patient was discharged from the hospital six days later without any postoperative complications. 


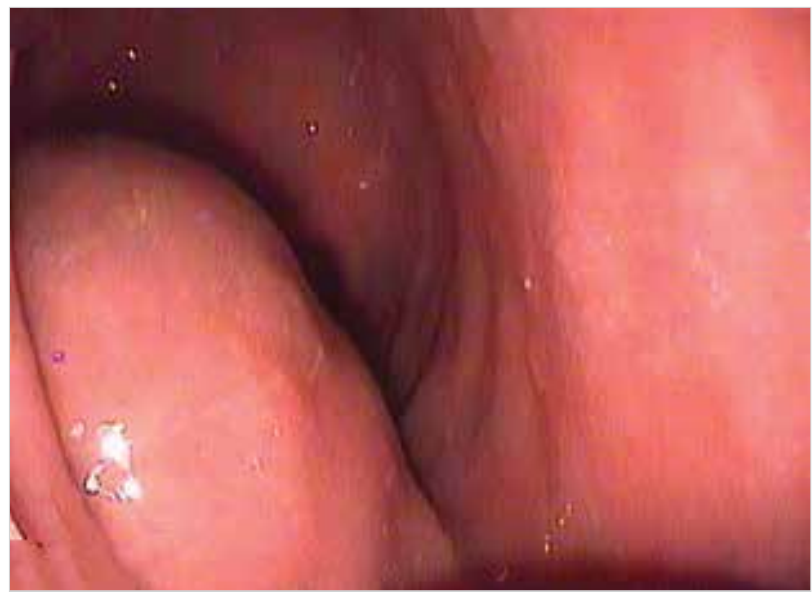

Figure 1. A submucosal mass in the antrum on endoscopic examination

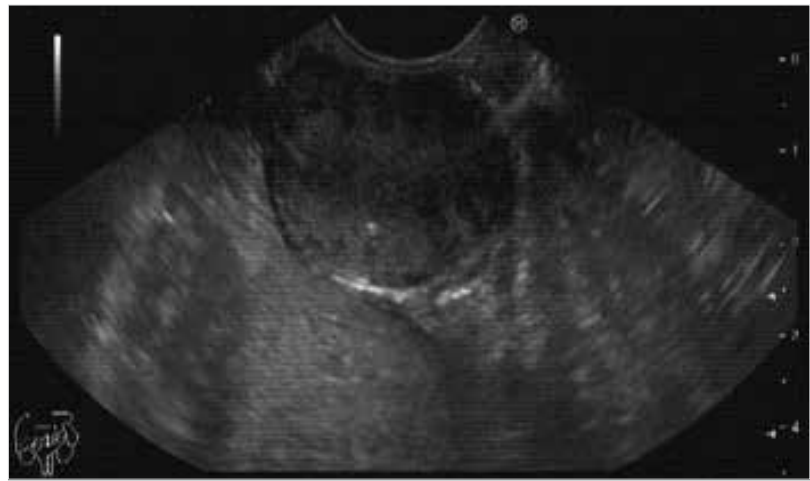

Figure 2. A hypervascularized submucosal mass with microcalcifications in muscularis propria of the antrum

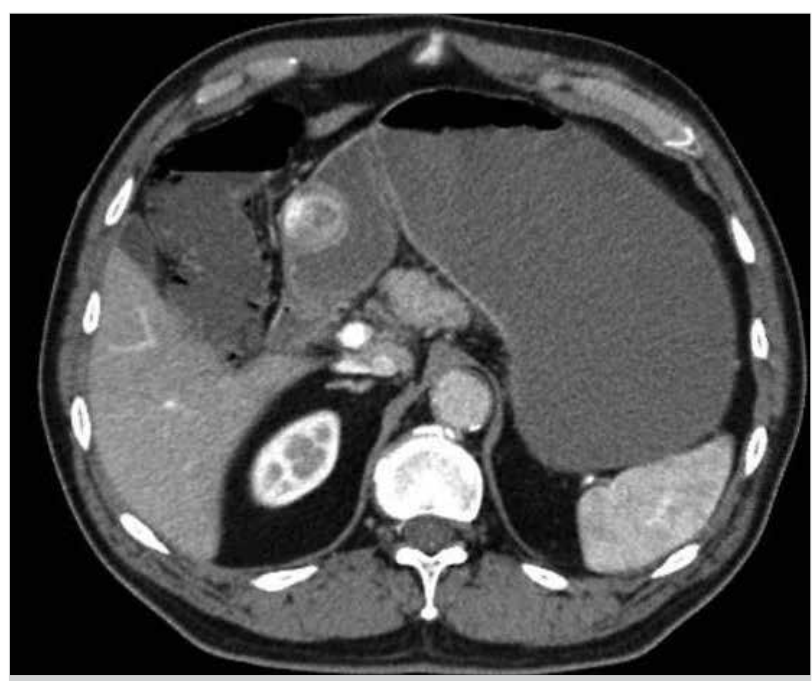

Figure 3. Well-circumscribed, homogeneously enhanced, solid, submucosal tumor on contrast-enhanced computed tomography

\section{DISCUSSION}

Glomus tumors arise from specialized cells of the glomus body. They are typically found in peripheral soft tissues, generally located in dermis and subcutis. Miettinen et al. (6) reported a series of 32 gastrointestinal glomus tumors, and 31 of them were gastric and one of them had cecal localization. According to them, gastric glomus tumors constitute $1 \%$ of the gastric stromal tumors. Gastric glomus tumors generally

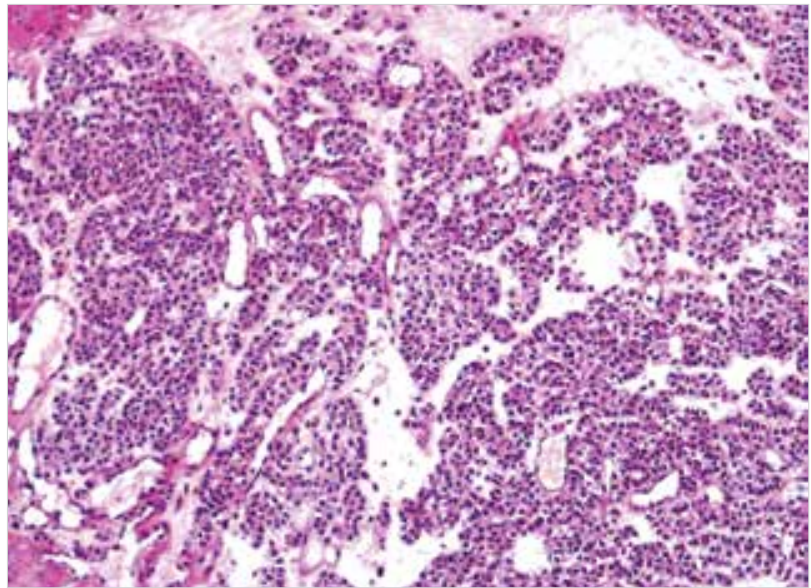

Figure 4. Glomus tumor: highly vascularized tumor with monomorphic, small, round, eosinophilic cells with a centrally located nuclei (H-EX100)

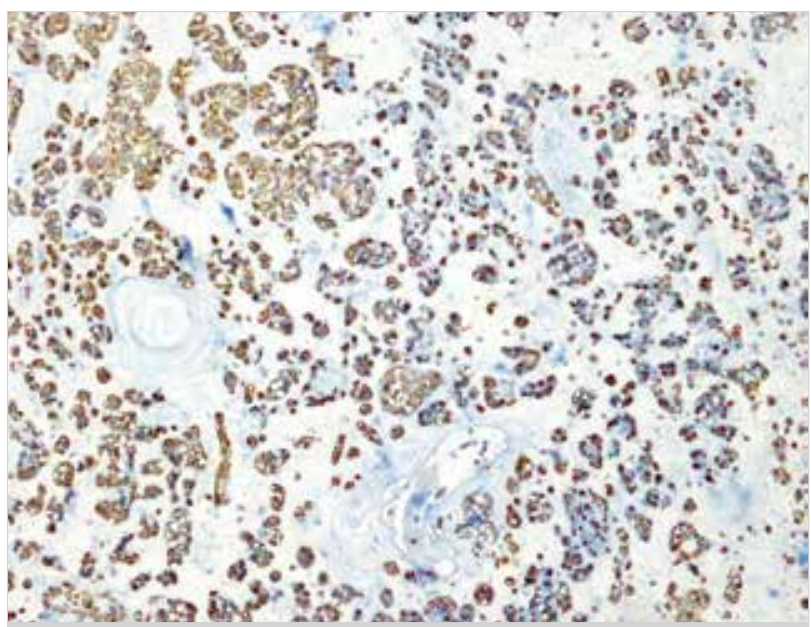

Figure 5. SMA was diffusely positive (100x)

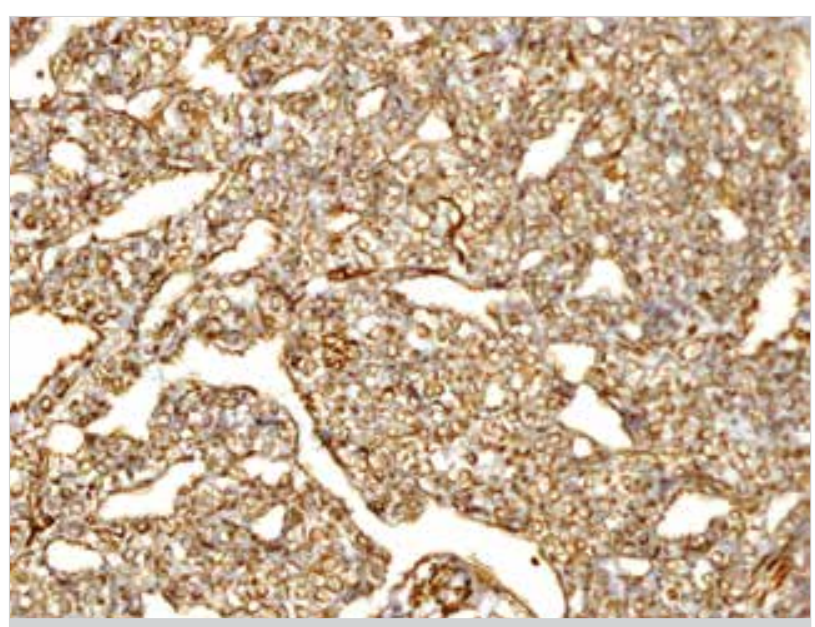

Figure 6. Vimentin was strongly and diffusely positive (200x)

located in the submucosa or muscularis propria of the gastric wall. The symptoms are nonspecific, e.g., abdominal discomfort, epigastric pain, and/or upper gastrointestinal bleeding (5). Gastric glomus tumors are generally solitary and located in the greater curvature $(7,8)$. They are commonly seen in the sixth decade (9). These tumors are more frequent in women than in men (6). Although the gender was uncommon, our patient had the other common features of the tumor. 
Most of the tumors have well-circumscribed borders and their size ranges from 1 to $22 \mathrm{~cm}$. In microscopic examination, the tumors compose of vascular channels surrounded by monomorphic, small round cells with sharp cell borders, centrally located nuclei, and inconspicuous nucleoli. Pleomorphism, atypia, mitosis, and necrosis are uncommon findings. Immunohistochemically, the tumor is strongly positive for SMA, vimentin, actin, calponin, type IV collagen, and laminin. CD 117 , DOG 1, S100, CD34, desmin, and neuroendocrine markers such as chromogranin, synaptophysin, neuron-specific enolase, CD56, CD57, and PGP 9.5 are negative $(1,5)$. Our patient's morphologic and immunohistochemical features were consistent with the literature.

The diagnosis of gastric glomus tumor can be challenging with endoscopic and radiologic findings, which can also be seen in other gastric stromal and mesenchymal tumors (4). Gastrointestinal stromal tumor paraganglioma, and NET should be considered for differential diagnosis. Gastrointestinal stromal tumor is the most common mesenchymal tumor of the stomach. Epithelioid type of GIST is one of the most important tumor in differential diagnosis of glomus tumor. Different from glomus tumor, GISTs are positive for CD117, DOG 1, and CD 34. Positivity for desmin, vimentin, and SMA are variable and S100 immunoreactivity is rare in glomus tumors $(1,9,10)$. Different from GIST, our tumor had distinctive dilated vascular structures. CD117 and DOG1 were applied to three tumor blocks and all were negative.

Paragangliomas are generally located in the retroperitoneum. They have Zellballen and alveolar pattern with accompanying thin-walled vessels. They characteristically show immunoreactivity with chromogranin, synaptophysin, and S-100 protein (1). All of these markers were negative in our submucosal localized gastric tumor.

Neuroendocrine tumors have nests and cords of oval and/or spindle large cells. The nuclei have salt and pepper chromatin pattern. They are positive for synaptophysin, chromogranin, and neuron-specific enolase $(1,2,11)$. Our patient's tumor had neither this morphologic pattern nor immunohistochemical features. Folpe et al. (12) proposed some criteria for malignant glomus tumors: deep location, size greater than $2 \mathrm{~cm}$, atypical mitosis, or high mitotic activity (5 mitoses/50 HPF) with moderate-to-high nuclear grade. Although the gastric site was accepted as a deep location in the past, it was understood that there are serious differences between gastric glomus and deep peripheral soft-tissue glomus tumors. According to the literature, absence of nuclear atypia and low mitotic activity did not exclude malignant potential, especially in larger tumors (>5 cm) (5). Symplastic glomus tumors are described as high nuclear grade tumors without any other malignant features. Glomus tumor of uncertain malignant potential term is used for tumors having high mitotic activity and additional criteria such as superficial location, large size, or deep localization (13). Our patient had a 5.5-cm tumor without mitosis and necrosis. The tumor had small monotonous cells with a centrally located nucleus. Nucleolus was not prominent. According to these features, our case was considered as benign and follow-up was recommended. Our patient is under control and out of disease for 18 months.

\section{CONCLUSION}

Gastric glomus tumors are rare mesenchymal tumors that are difficult to diagnose before excision. Their clinical, radiologic, endoscopic, and even cytologic features can overlap with the common stromal and mesenchymal gastric tumors. After the removal, morphologic features and immunohistochemical examination play an important role for the diagnosis of gastric glomus tumor.

Informed Consent: Written informed consent was obtained from patient who participated in this study.

Peer-review: Externally peer-reviewed.

Author Contributions: Concept - P.Y., Z.G., D.S.A., F.Ü.M. ,B.B.; Design - P.Y., Z.G., D.S.A., F.Ü.M., B.B.; Supervision - Z.G., D.S.A.; Resource - P.Y., F.Ü.M., B.B.; Materials - P.Y. Z.G., D.S.A., F.Ü.M., B.B.; Data Collection and/ or Processing - P.Y., F.Ü.M., B.B.; Analysis and/or Interpretation - P.Y., Z.G., D.S.A.; Literature Search - P.Y.; Writing Manuscript - P. Y., Z.G., D.S.A., F.Ü.M., B.B.; Critical Reviews - P.Y., Z.G., D.S.A.

Conflict of Interest: No conflict of interest was declared by the authors.

Financial Disclosure: The authors declared that this study has received no financial support.

\section{REFERENCES}

1. Fang $\mathrm{HQ}$, Yang J, Zhang FF, Cui Y, Han AJ. Clinicopathological features of gastric glomus tumor. World J Gastroenterol 2010; 16: 4616-4620. [CrossRef]

2. Nascimento EF, Fonte FP, Mendonca RL, Nonose R, de Souza CA, Martinez CA. Glomus tumor of the stomach: a rare cause of upper gastrointestinal bleeding. Case Rep Surg 2011; 371082. [CrossRef]

3. Kay S, Callahan WP Jr, Murray MR, Randall HT, Stout AP.Glomus tumors of the stomach. Cancer 1951; 4: 726-736. [CrossRef]

4. Vassiliou I, Tympa A, Theodosopoulos T, Dafnios N, Fragulidis G, Koureas A, Kairi E. Gastric glomus tumor: A case report World J Surg Oncol 2010; 8: 19. [CrossRef]

5. Kang G, Park HJ, Kim JY, Choi D, Min BH, Lee JH, et al. Glomus tumor of the stomach: a clinicopathologic analysis of 10 cases and review of the literature. Gut Liver 2012; 6: 52-57. [CrossRef]

6. Miettinen M, Paal E, Lasota J, Sobin LH. Gastrointestinal glomus tumors: aclinicopathologic, immunohistochemical, and molecular genetic study of 32 cases. Am J Surg Pathol 2002, 26: 301-311. [CrossRef]

7. Haque S, Modlin IM, West AB. Multiple glomus tumors of the stomach with intravascular spread.Am J Surg Pathol 1992, 16: 291-299. [CrossRef]

8. Debol SM, Stanley MW, Mallery S, Sawinski E, Bardales RH. Glomus tumor of the stomach: cytologic diagnosis by endoscopic ultrasound-guided fine-needle aspiration. Diagn Cytopathol 2003, 28: 316-321. [CrossRef]

9. Miettinen M, Blay JY, Sobin LH. Mesenchymal tumors of stomach in Hamilton SR, Aaltonen LA (eds) WHO classification of Tumours. Pathology and Genetics of Tumours of Pathology the Digestive System. IARC Press, Lyon; 2000. p65.

10. Wang ZB, Yuan J, Shi HY. Features of gastric glomus tumor: a clinicopathologic, immunohistochemical and molecular retrospective study. Int J Clin Exp Pathol 2014; 7: 1438-1448.

11. Usta U, Özyilmaz F, Özdemir Ç, Hüseyinova G, Sezer AY. Glomus Tumor of the Stomach. Trakya Univ Tip Fak Derg 2007; 24: 141-145.

12. Folpe AL, Fanburg-Smith JC, Miettinen M. Atypical and malignant glomus tumor: analysis of 52 cases, with proposal for the reclassification of glomus tumors. Am J Surg Pathol 2001; 25: 1-12. [CrossRef]

13. Nalbant $O A$, Temiz P, Vural $S$, Keleş MC. Midenin Glomus Tümörü: Olgu Sunumu. Turkish Journal of Pathology 2010; 26: 74-77. [CrossRef] 